\title{
NRAS Negative
}

National Cancer Institute

\section{Source}

National Cancer Institute. NRAS Negative. NCI Thesaurus. Code C142837.

An indication that NRAS expression has not been detected in a sample. 